\title{
Fallen in the Face of COVID-19: Graduates of Cuba's Latin American School of Medicine (ELAM)
}

\section{Gail Reed MS}

The 2020 fall semester at Havana's Latin American School of Medicine (ELAM) began on an especially somber note: honoring 17 of its alumni felled as they battled COVID-19 in their home countries and beyond. A few were recent graduates among the 30,047 from 118 countries who received scholarships from Cuba to study medicine at ELAM. Others were members of its first graduating class in 2005.

Their service on the front lines during the pandemic reflects the school's mission to train low-income students the world over who pledge to care for communities and their patients, irre- spective of ability to pay... and often in public health facilities at no charge.

MEDICC Review joins fellow ELAM graduates, students and faculty in paying tribute to the service of these talented, dedicated young health professionals, and expresses our deepest condolences to their families, friends, colleagues and mentors.

Many of the pictures in this photo-feature are not publication quality. That's not why they were taken. Rest in peace, service, and confidence in the fact that health for all is possible.

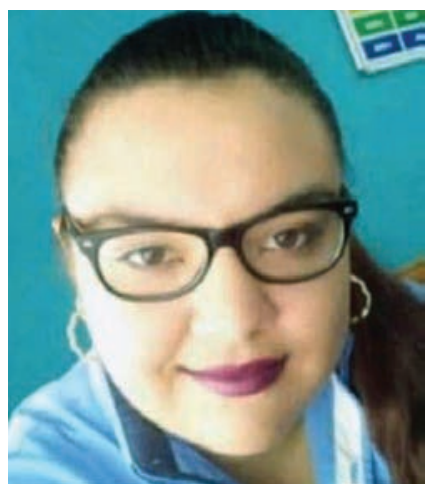

Dr. Ericka Julissa Flores Torres (1981-2020)

Peru

ELAM Class of 2005

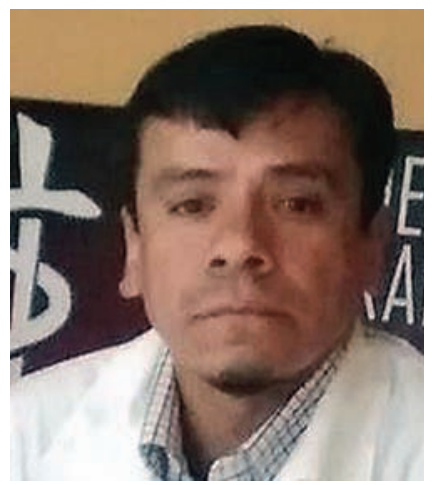

Dr. Luis Fernando Orozco Andrade (1977-2020)

Guatemala

ELAM Class of 2005

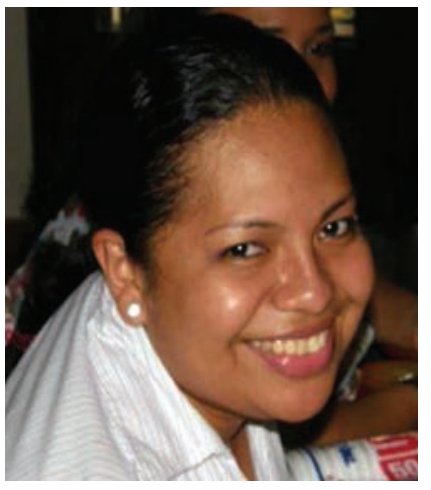

Dr. Yessenia Herrera Ruiz (1981-2020)

Panama

ELAM Class of 2005

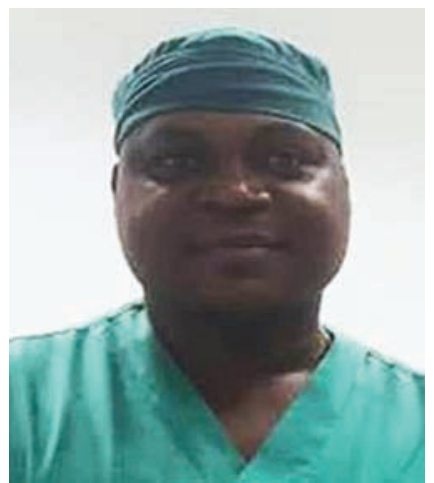

Dr. Ambrosio-Moyo Ondo Ayecaba (1974-2020)

Equatorial Guinea

ELAM Class of 2007

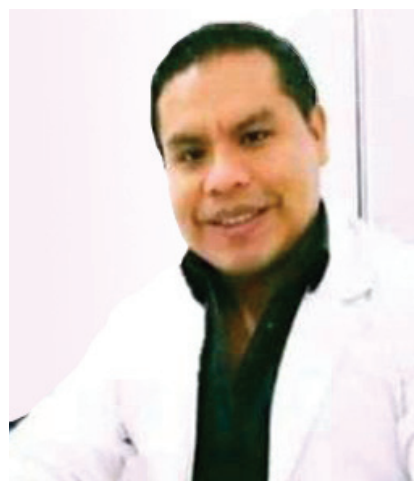

Dr. Orlando Julio Isacc King (1979-2020)

Venezuela

ELAM Class of 2005

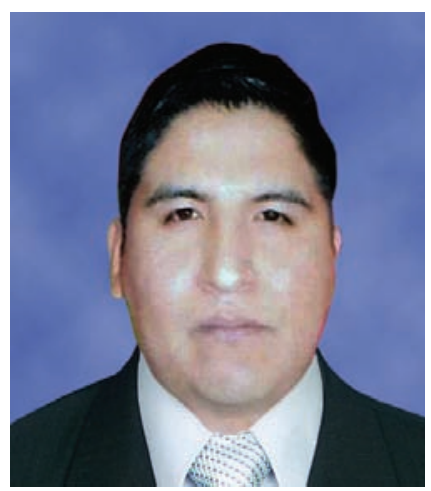

Dr. Roger Layme Salgueiro (1984-2020)

Bolivia

ELAM Class of 2011 


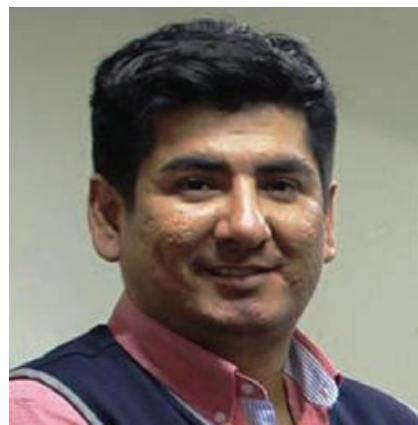

Dr. José Humberto Paredes Abanto (1988-2020)

Peru

ELAM Class of 2011

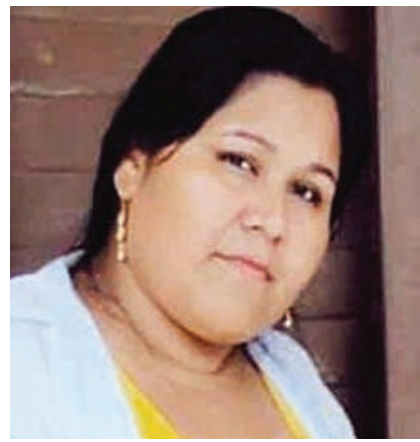

Dr. Sara Chambi Méndez (1988-2020)

Bolivia

ELAM Class of 2012

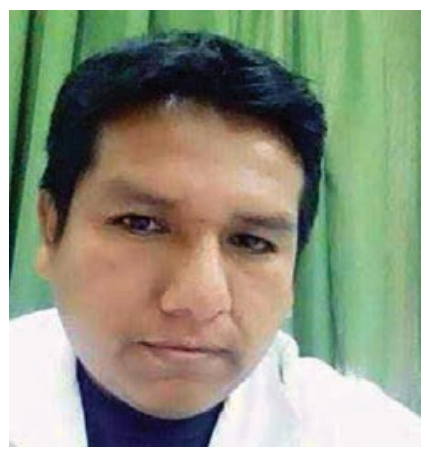

Dr. Juan Orellana Cardenas (1986-2020)

Bolivia

ELAM Class of 2012

Dr. Jhonny Josué Nilton Villegas Atora (1986-2020)

Bolivia

ELAM Class of 2012

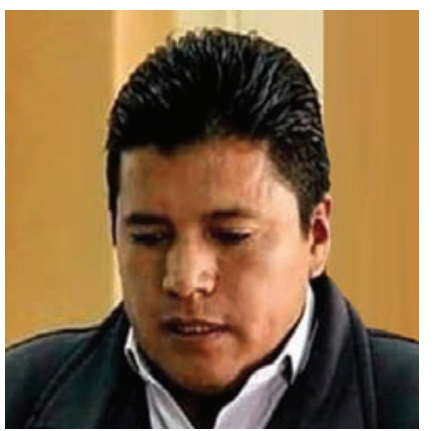

Dr. Edgar Patricio Aynaguano Uño (1984-2020)

Ecuador

ELAM Class of 2012

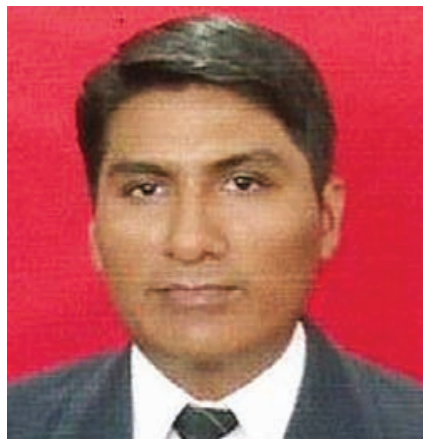

Dr. Nemecio Choque Niño (1983-2020)

Bolivia

ELAM Class of 2012

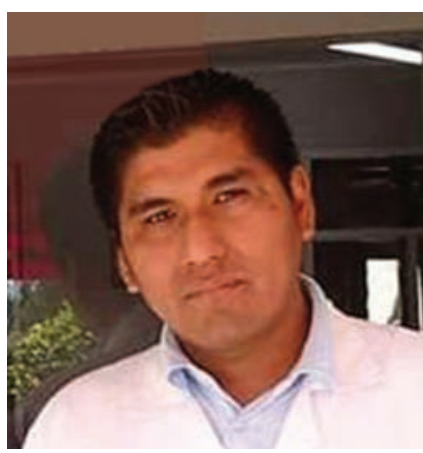

Dr. Hebert Ortuño Vallejos (1985-2020)

Bolivia

ELAM Class of 2012

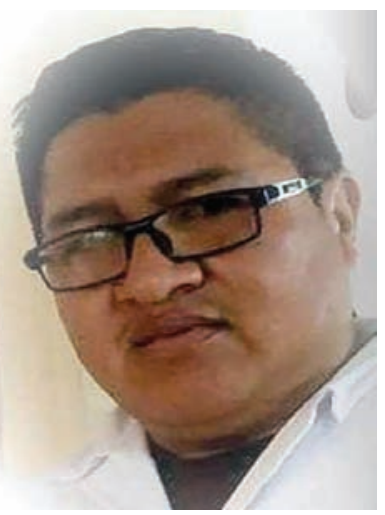

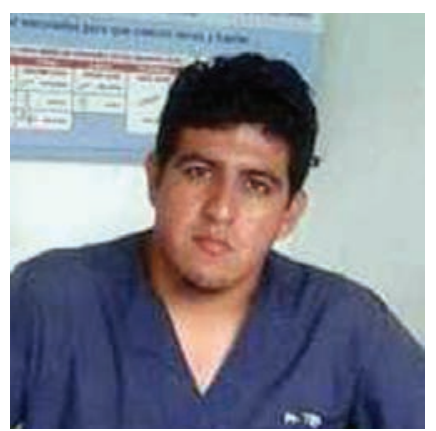

Dr. Mariano Luis Barrios Lijerón (1989-2020)

Bolivia

ELAM Class of 2012

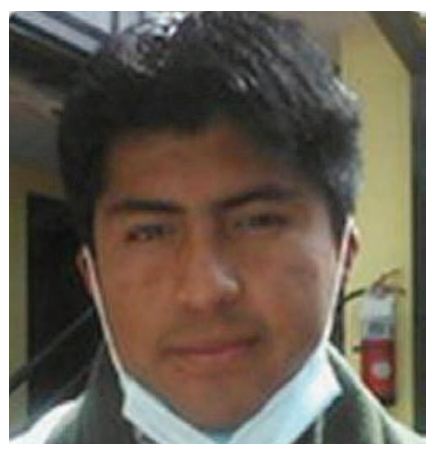

Dr. Martín Adolfo Morales Figueredo (1986-2020)

Bolivia

ELAM Class of 2012

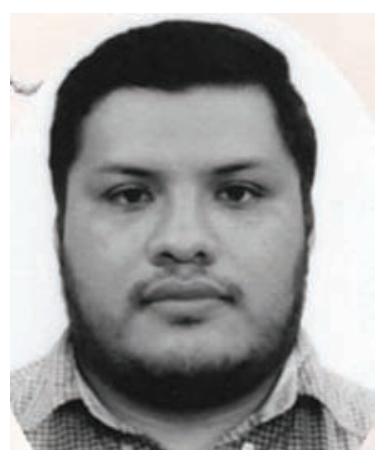

Dr. Job Gerardo Villanueva Núñez (1987-2020)

Honduras

ELAM Class of 2012

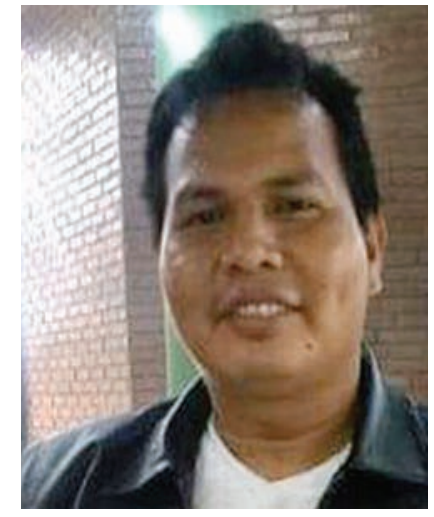

Dr. Alberto Arteaga Jiménez (1985-2020)

Bolivia

ELAM Class of 2013

https://doi.org/10.37757/MR2020.V22.N4.13 